\title{
Modeling Off-Shore Wind Turbine Construction Project Subject to Impact of Wind Uncertainty
}

\author{
Sy-Jye Guo \\ Department of Civil Engineering, National Taiwan University, Taiwan \\ Email: sjguo@ntu.edu.tw
}

How to cite this paper: Guo, S.-J. (2019) Modeling Off-Shore Wind Turbine Construction Project Subject to Impact of Wind Uncertainty. World Journal of Engineering and Technology, 7, 38-47. https://doi.org/10.4236/wjet.2019.72B005

Received: February 19, 2019a

Accepted: May 14, 2019

Published: May 17, 2019

\begin{abstract}
Offshore wind farm is a key item in green energy and sustainable development. The Taiwan strait owns the world-class wind farm with average wind speed of $12 \mathrm{~m} / \mathrm{s}$ and a potential for 3000 hours/year of power generation. Compared to wind turbines on land, the offshore wind turbine provide more stable power and less obstacles as well as less power loss. The potential and advantages of offshore wind farm development in the Taiwan strait has become the aims of the Taiwan government policy from now to 2025. This research will collect the historical climate data (wind and wave) of the Taiwan offshore wind farm in the Chan-hwa county. Combined the productivity loss respected to the installation of wind turbine due to different wind speed effect, as well as the productivity loss respected to the construction of pile foundation due to different wave height effect, this study will build up a total project duration forecast system based on the historical climate data of the offshore wind farm. Even the literature views from the experienced projects in North Europe including UK, Netherland and Spain, the climate uncertainty still plays a significant factor of the total construction duration for offshore wind farm. The results of this research can provide a more scientific and reliable duration forecast for future offshore wind farms construction in Taiwan.
\end{abstract}

\section{Keywords}

Offshore Wind Farm, Project Duration Forecast, Climate, Wind, Wave

\section{Introduction}

Due to the rapid depletion of natural resource, wind energy has been obtaining a considerable attention as an alternative to conventional fossil, coal, or nuclear sources of energy in recent decades. Because of its characteristics of cleanness, inexhaustibility, low pollution and low cost, wind energy becomes one of the 
most promising renewable energy sources worldwide. Therefore, many countries are increasingly interested in establishing wind farms with multi-megawatt sized wind turbines for sustainable green energy developments. It is foreseeable that a large number of wind turbine construction projects will be carried out worldwide in the near future.

Wind turbine construction projects are normally carried out in an outdoor environment, particularly onshore or offshore with plentiful of wind energy. Weather can affect construction tasks in various ways [1] [2] [3]. Hence, the construction tasks of wind farm projects are inevitably affected by the presence of wind uncertainty. For example, lifting tasks of wind turbine construction projects are very sensitive to the adverse impact of wind uncertainty, which often leads to significant loss of productivity and, even worse, complete suspension of construction tasks as a result of severe impact of strong wind. Accordingly, wind is a significant weather risk for productivity loss and schedule delay in wind turbine construction projects [4].

Forecasting the future durations for wind-sensitive tasks in advance is useful for schedule planning in order to avoid the adverse impact of wind uncertainties, which often lead to productivity loss. Accordingly, accurate predictions of future duration for wind-sensitive tasks based on productivity loss are essential to develop an optimal schedule strategy. However, the estimations of productivity loss are usually gathered from professionals' subjective assessments using linguistic descriptions such as "the productivity loss of lifting task is about $40 \%$ in fresh breeze condition" which are innately imprecise or fuzzy. On the other hand, wind speed data affecting productivity are numerical. Accordingly, information with regard to the impact of wind uncertainties on productivity loss is a mixture of fuzzy data and crisp data. In order to assess the impact of wind uncertainties which are linguistic, vagueness, and subjective in nature, fuzzy sets-based technique can be utilized [5].

With the assistance of professional expertise, the incorporation of fuzzy-set approach, as well as the utilization of historical wind speed data, this research presents a fuzzy duration forecast model for wind turbine construction project subject to the impact of wind uncertainties. An appropriate duration for each wind-sensitive task based on no-wind condition can be assigned based on a rule of thumb; afterwards, the forecasted duration subject to the impact of wind uncertainties can be derived by the proposed model. An application example using this model to forecast the duration of wind-sensitive tasks is presented using actual wind speed data from Taiwan. This model is easier to follow and simpler to apply. By employing this approach, the duration can be more accurately predicted even though without much relevant working experience provided

\section{Analysis of Measured Wind Data}

Since no wind events can be accurately forecasted, instead of experiences and judgments, historical wind speed data become mandatory parameters in devel- 
oping the fuzzy duration forecast model for wind turbine construction project subject to the impact of wind uncertainty. Usually, these data can be obtained from the Weather Authority. The Central Weather Bureau (CWB) in Taiwan has set up many meteorological stations across Taiwan since 1961. Consequently, over decades of long-term measured data sources of hourly mean wind speed can provide environmental information for the application of the proposed fuzzy duration forecast model.

In reality, the general public does not recognize wind levels as expressed quantitatively by the exact amount of wind speed, such as $6.2 \mathrm{~m} / \mathrm{s}, 6.5 \mathrm{~m} / \mathrm{s}$, or 8.8 $\mathrm{m} / \mathrm{s}$. Instead, people perceive wind levels as described linguistically, such as calm, light air, light breeze, gentle breeze, moderate breeze, fresh breeze, strong breeze, and near gale. For classifying various levels of wind with corresponding range of wind speed, the Beaufort wind force scale is the most widely used system in many countries, including Taiwan, as shown in Table 1. The Beaufort scale defines and classified thirteen levels of wind, i.e. calm, light air, light breeze, gentle breeze, moderate breeze, fresh breeze, strong breeze, near gale, gale, strong gale, storm, violent storm, and hurricane, as well as their corresponding range of wind speed. The classification describes effects of various wind levels, from Beaufort scale zero-smoke rises vertically to Beaufort scale 12-causing violence and destruction is based on observation of land or sea condition rather than accurate measurement. In Taiwan, Beaufort scale 8 through Beaufort scale 11 is referred to as mild typhoon and Beaufort scale 12 is referred to as hurricane. Since there will not be any wind turbine construction task carried out during typhoon and hurricane situation, Beaufort 0 (calm) to Beaufort 7 (near gale) is, hence, adopted as the scales of wind force in this research.

\section{Fuzzy Duration Forecast Model}

\subsection{Identification of Wind-Sensitive Tasks}

Although wind is a significant weather risk for project scheduling, there is only limited understanding of how wind may affect wind turbine construction projects. In order to develop the fuzzy duration forecast model for wind turbine construction project subject to the impact of wind uncertainty, the first step is to identify wind-sensitive tasks. Through site visits and work breakdown structure (WBS) analysis, several tasks in wind turbine construction projects are significantly sensitive to the impact of wind uncertainty, including 1) Erection of Tower of Wind Turbine, 2) Cable Laying \& Wiring in Tower \& Nacelle, 3) Commissioning Test \& Inspection, 4) Function Co-Test with Owner, and 5) Test Run \& 96-hr Trial Operation. In addition, the task of "Erection of Tower of Wind Turbine" takes place within a few days and involves three steps. First, the lower, middle, and upper tower segments are delivered and are assembled respectively by using two heavy cranes, one used to lift and the other used to keep steady. Secondly, the nacelle, which houses the electrical generator, is mounted on top of the tower. Thirdly, the three rotor blades are connected to the hub, 
Table 1. The beaufort wind force scale.

\begin{tabular}{|c|c|c|c|}
\hline Beaufort Number & Description & Wind Speed $(\mathrm{m} / \mathrm{s})$ & Land condition \\
\hline 0 & Calm & $<0.3$ & Calm. Smoke rises vertically. \\
\hline 1 & Light air & $0.3-1.5$ & $\begin{array}{l}\text { Smoke drift indicates wind direction. } \\
\text { Leaves and wind vanes are stationary. }\end{array}$ \\
\hline 2 & Light breeze & $1.6-3.3$ & $\begin{array}{l}\text { Wind felt on exposed skin. Leaves rustle. } \\
\text { Wind vanes begin to move. }\end{array}$ \\
\hline 3 & Gentle breeze & $3.4-5.4$ & $\begin{array}{l}\text { Leaves and small twigs constantly } \\
\text { moving, light flags extended. }\end{array}$ \\
\hline 4 & $\begin{array}{l}\text { Moderate } \\
\text { breeze }\end{array}$ & $5.5-7.9$ & $\begin{array}{l}\text { Dust and loose paper raised. Small } \\
\text { branches begin to move. }\end{array}$ \\
\hline 5 & Fresh breeze & $8.0-10.7$ & $\begin{array}{l}\text { Branches of a moderate size move. Small } \\
\text { trees in leaf begin to sway. }\end{array}$ \\
\hline 6 & Strong breeze & $10.8-13.8$ & $\begin{array}{l}\text { Large branches in motion. Whistling } \\
\text { heard in overhead wires. Umbrella use } \\
\text { becomes difficult. Empty plastic bins tips } \\
\text { over. }\end{array}$ \\
\hline 7 & Near gale & $13.9-17.1$ & $\begin{array}{l}\text { Whole trees in motion. Effort needed to } \\
\text { walk against the wind. }\end{array}$ \\
\hline 8 & Gale & $17.2-20.7$ & $\begin{array}{l}\text { Some twigs broken from trees. Cars veer } \\
\text { on road. Progress on foot is seriously } \\
\text { impended. }\end{array}$ \\
\hline 9 & Strong gale & $20.8-24.4$ & $\begin{array}{l}\text { Some branches break off trees, and some } \\
\text { small trees blow over. } \\
\text { Construction/temporary signs and } \\
\text { barricades blow over. }\end{array}$ \\
\hline 10 & Storm & $24.5-28.4$ & $\begin{array}{l}\text { Trees are broken off or uprooted, } \\
\text { structural damage likely. }\end{array}$ \\
\hline 11 & Violent storm & $28.5-32.6$ & $\begin{array}{l}\text { Widespread vegetation and structural } \\
\text { damage likely. }\end{array}$ \\
\hline 12 & Hurricane force & $>32.7$ & $\begin{array}{l}\text { Severe widespread damage to vegetation } \\
\text { and structures. Debris and unsecured } \\
\text { objects are hurled about. }\end{array}$ \\
\hline
\end{tabular}

which is then lifted by cranes and connected to the nacelle. Table 2 lists the logic of performing the tasks in the network as well as the predecessors and the duration under no-wind basis estimated based on a rule of thumb. Besides, the wind over $10 \mathrm{~m} / \mathrm{s}$ of speed will significantly affect the productivity of the task of "Erection of Tower of Wind Turbine" as well as the task of "Cable Laying \& Wiring in Tower \& Nacelle". On the other hand, the task of "Commissioning Test \& Inspection", the task of "Function Co-Test with Owner", as well as the task of "Test Run \& 96-hr Trial Operation" cannot be successfully completed without the assistance of higher level of wind.

\subsection{Empirical Productivity Loss for Wind-Sensitive Tasks}

Different wind-sensitive tasks of wind turbine construction project subject to different levels of wind often result in different productivity losses. The productivity 
Table 2. Information of the wind-sensitive tasks in wind turbine construction project.

\begin{tabular}{cccc}
\hline & Task & No-wind duration (day) & Predecessor \\
\hline 1 & Erection of Tower of Wind Turbine & & \\
$1-1$ & Lifting \& Installing Tower (Lower, Middle, \& Upper) & 1 & \\
$1-2$ & Lifting \& Installing Nacelle and Generator & 1 & $1-1$ \\
$1-3$ & Lifting \& Installing Rotor Hub and Blades & 1 & $1-2$ \\
2 & Cable Laying \& Wiring in Tower \& Nacelle & 3 & $1-3$ \\
3 & Commissioning Test \& Inspection & 3 & 2 \\
4 & Function Co-Test with Owner & 1 & 3 \\
5 & Test Run \& 96-hr Trial Operation & 4 & 4 \\
\hline
\end{tabular}

loss is expressed in percentage in this research. In the no-wind scenario, the productivity loss is $0 \%$ and the task can be fully in progress on schedule. In comparison, $50 \%$ of productivity loss represents that only half the task can be progressing on the same schedule. In order to quantify the impact of different levels of wind in terms of productivity loss on wind-sensitive tasks, professional expertise and opinion should be investigated. Hence, surveys of 50 questionnaires have been administered to 50 experienced designers, site engineers, and supervisors who had extensive experience of over five years involving several various wind turbine construction projects. The questionnaire results in terms of empirical productivity loss $(E P L)$ were then reviewed and summarized to the final consequences of the survey by combining the variations among individual responses. A typical result is shown in Table 3.

According to the survey results in Table 3 , the empirical productivity loss $(E P L)$ of task of Lifting \& Installing Lower Tower subject to the impact of various levels of wind can be expressed as an $8 \times 1$ matrix as Equation (1). Similarly, the empirical productivity loss $(E P L)$ of other wind-sensitive tasks can also be expressed as the same matrix form.

$$
E P L=\left[\begin{array}{c}
0 \\
0 \\
0.6 \\
1.2 \\
4.4 \\
41.3 \\
69.0 \\
96.2
\end{array}\right]
$$

\subsection{Fuzzy Set Approach}

Instead of crisp data of wind speed, questionnaire respondents recognize various wind levels as described linguistically, such as calm, light air, light breeze, gentle breeze, moderate breeze, fresh breeze, strong breeze, and near gale, as well as expressed qualitatively, such as smoke rises vertically or dust and loose paper raised. For instance, the term "Calm" implies that smoke rises vertically and the 
Table 3. Example of questionnaire result for empirical productivity loss.

\begin{tabular}{ccccccccc}
\hline \multicolumn{10}{c}{ Empirical Productivity Loss (\%) } \\
\hline Task & Calm & Light air & $\begin{array}{c}\text { Light } \\
\text { breeze }\end{array}$ & $\begin{array}{c}\text { Gentle } \\
\text { breeze }\end{array}$ & $\begin{array}{c}\text { Moderate } \\
\text { breeze }\end{array}$ & $\begin{array}{c}\text { Fresh } \\
\text { breeze }\end{array}$ & $\begin{array}{c}\text { Strong } \\
\text { breeze }\end{array}$ & $\begin{array}{c}\text { Near } \\
\text { gale }\end{array}$ \\
\hline $\begin{array}{c}\text { Lifting \& Installing } \\
\text { Lower Tower }\end{array}$ & 0 & 0 & 0.6 & 1.2 & 4.4 & 41.3 & 69 & 96.2 \\
\hline
\end{tabular}

Unit: Percentage (\%).

term "near gale" implies whole trees in motion and effort needed to walk against the wind as shown in Table 1. As results, the wind level recognized by respondents may not be consistent to the range of wind speed classified in the Beaufort wind force scale. Besides, various experts may have different wind level recognitions. These cause the empirical productivity loss (EPL) naturally imprecise. These linguistic and qualitatively terms of wind levels can be translated into mathematical measures using fuzzy set approach. The fuzzy set approach adopts the membership function to describe uncertainty or vagueness. The membership function assigns a membership value in the interval $[0,1]$ to an element of a fuzzy set for representing if the element belongs to the set. Each Beaufort scale is corresponding to a range of wind speed determined in the Beaufort scale of wind force as shown in Table 1. For example, the corresponding range of wind speed in Beaufort 4 (moderate breeze) is 5.5 through $7.9 \mathrm{~m} / \mathrm{s}$, the corresponding range of wind speed in Beaufort 5 (fresh breeze) is 8.0 through $10.7 \mathrm{~m} / \mathrm{s}$, and the corresponding range of wind speed in Beaufort 6 (strong breeze) is 10.8 through $13.8 \mathrm{~m} / \mathrm{s}$. Hence, based on the range of wind speed in Beaufort scale, trapezoidal typed membership functions are utilized to characterize fuzzy sets of various wind level. Since the land condition caused by each Beaufort scale of wind force is different, it is obvious that part of the corresponding range of wind speed would be the core of the membership function in each Beaufort scale and the other wind speed would be the support of the membership function. The linear relation is used to model the gradual transition between the support and the core of the membership function. Besides, the middle value of wind speed between two consecutive Beaufort scales can be regarded as 50\% degree of membership to each of those two consecutive Beaufort scales. For instance, the wind speed of $7.95 \mathrm{~m} / \mathrm{s}$ can be regarded as $50 \%$ degree of membership to Beaufort 4 (moderate breeze) and Beaufort 5 (fresh breeze), respectively. Also, the wind speed of 10.75 $\mathrm{m} / \mathrm{s}$ can be regarded as $50 \%$ degree of membership to Beaufort 5 (fresh breeze) and Beaufort 6 (strong breeze), respectively. Hence, based on the above mentioned principles, trapezoidal fuzzy membership functions $\mathrm{u}(\mathrm{x})$ are developed herein to relate the exact amount of wind speed to fuzzy descriptions of different levels of wind, as illustrated in Figure 1. They overlap to account for the uncertainty on the boundaries.

As shown in Figure 1, the fuzzy set W of wind can be defined as a $1 \times 8 \mathrm{ma}-$ trix as Equation (11). For instance, given hourly mean wind speed of $8.31 \mathrm{~m} / \mathrm{s}$, the fuzzy set W of wind can be obtained as in Equation (2). 


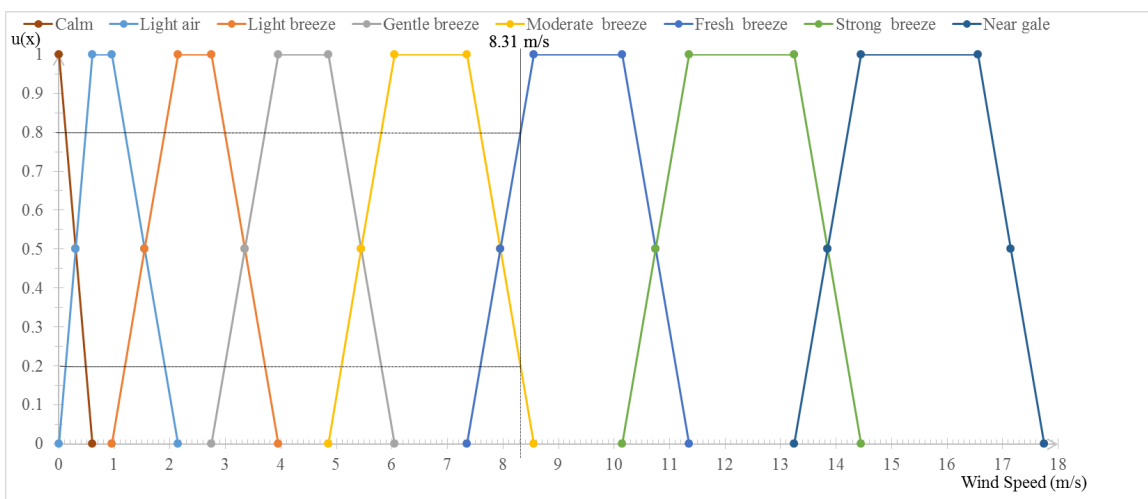

Figure 1. Trapezoidal fuzzy membership function $\mathrm{u}(\mathrm{x})$.

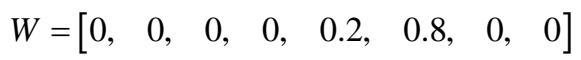

Thus, the membership values, or the degree of belong to the Beaufort scale of wind, for moderate breeze and fresh breeze is 0.2 and 0.8 , respectively. Other wind levels are assigned a membership value of 0 .

\subsection{Productivity Loss (PL)}

The productivity loss $(P L)$ is the major input for the fuzzy duration forecast model to determine the duration to complete tasks and project. Productivity loss $(P L)$ is usually difficult to precisely estimate because of uncertainties and vague information. Combining the empirical productivity loss (EPL) obtained from questionnaire survey based on each Beaufort scale of wind with the fuzzy set $W$ of wind subjected to a specific hourly mean wind speed, the crisp value of productivity loss $(P L)$ due to a particular wind speed for a specific task can then be calculated as in Equation (3):

$$
P L=W \times E P L
$$

In this example, the crisp value of productivity loss $(P L)$ of task of Lifting \& Installing Lower Tower subjected to $8.31 \mathrm{~m} / \mathrm{s}$ of hourly mean wind speed is calculated as in Equation (4).

$$
P L=W \times \mathrm{EPL}=\left[\begin{array}{llllllll}
0, & 0, & 0, & 0, & 0.2, & 0.8, & 0, & 0
\end{array}\right]\left[\begin{array}{c}
0 \\
0 \\
0.6 \\
1.2 \\
4.4 \\
41.3 \\
69.0 \\
96.2
\end{array}\right]=34.28 \%
$$

\subsection{Criteria for Task Duration Formulation}

Once the productivity loss $(P L)$ is determined, the remaining productivity $(R P)$ can be calculated as in Equation (5).

$$
R P=1-P L
$$


Then the duration of a specific task can be calculated by accumulating the remaining productivity $(R P)$ as in Equation (6). The $N$ is the minimum units to ensure that the summation of remaining productivity $(R P)$ reaches $U$. In other words, $N$ is the duration to complete the task subjected to the impact of wind.

$$
\sum_{i=1}^{N}\left(R P_{i}\right) \geq \mathrm{U}
$$

where

$\left(R P_{\mathrm{i}}\right)=$ the remaining productivity under the impact of wind;

$\mathrm{U}=$ the task duration under the no-wind situation; that is, the total productivity required to complete the task under the no-wind situation.

$N=$ the task duration subject to the impact of wind.

\section{Model Framework}

In this study, the Microsoft Project was employed as the platform to construct fuzzy duration forecast model for wind turbine construction project subject to the impact of wind. The Microsoft Project is very popular software for project scheduling due to its user-friendly graphical interface, capability of integration, and other advanced sophisticated features. The historical data of hourly mean wind speed are collected and organized in the Microsoft Excel as a database to be the model's input file. Other interfaces for importing data such as the starting dates of projects are programmed by Visual Basic to link with Microsoft Project. All the functional capabilities of Microsoft Project are still available for the model user.

In this fuzzy duration forecast model, the height of turbine hub, the location of the construction project as well as the project's starting date must be specified at first. The model is then automatically linked with the related historical wind speed data and transfers them to the wind speed data at the hub height. A selection interface was built into the model for the user to select the year(s) of wind speed data for simulation. This model also contains the results of questionnaire surveys and expert reviews for default input that can be revised by the user for possible modification. Figure 2 displays the framework for fuzzy duration forecast model.

\section{Conclusions}

Many wind turbine construction projects will be carried out worldwide in the future for sustainable green energy development. However, wind turbine construction projects significantly suffer from the impact of wind uncertainty which usually results in raising contractor's schedule risks on a calendar-day basis. This study presents a fuzzy duration forecast model to quantify the impact of wind uncertainty in terms of productivity loss $(P L)$ and to forecast the duration for wind-sensitive tasks of wind turbine construction projects subject to the impact of various scales of wind. Based on the results simulated, reasonable durations of wind-sensitive tasks can be assigned. In addition, an actual wind turbine construction project with hypothetical start date in 2008 to 2013 is presented to 


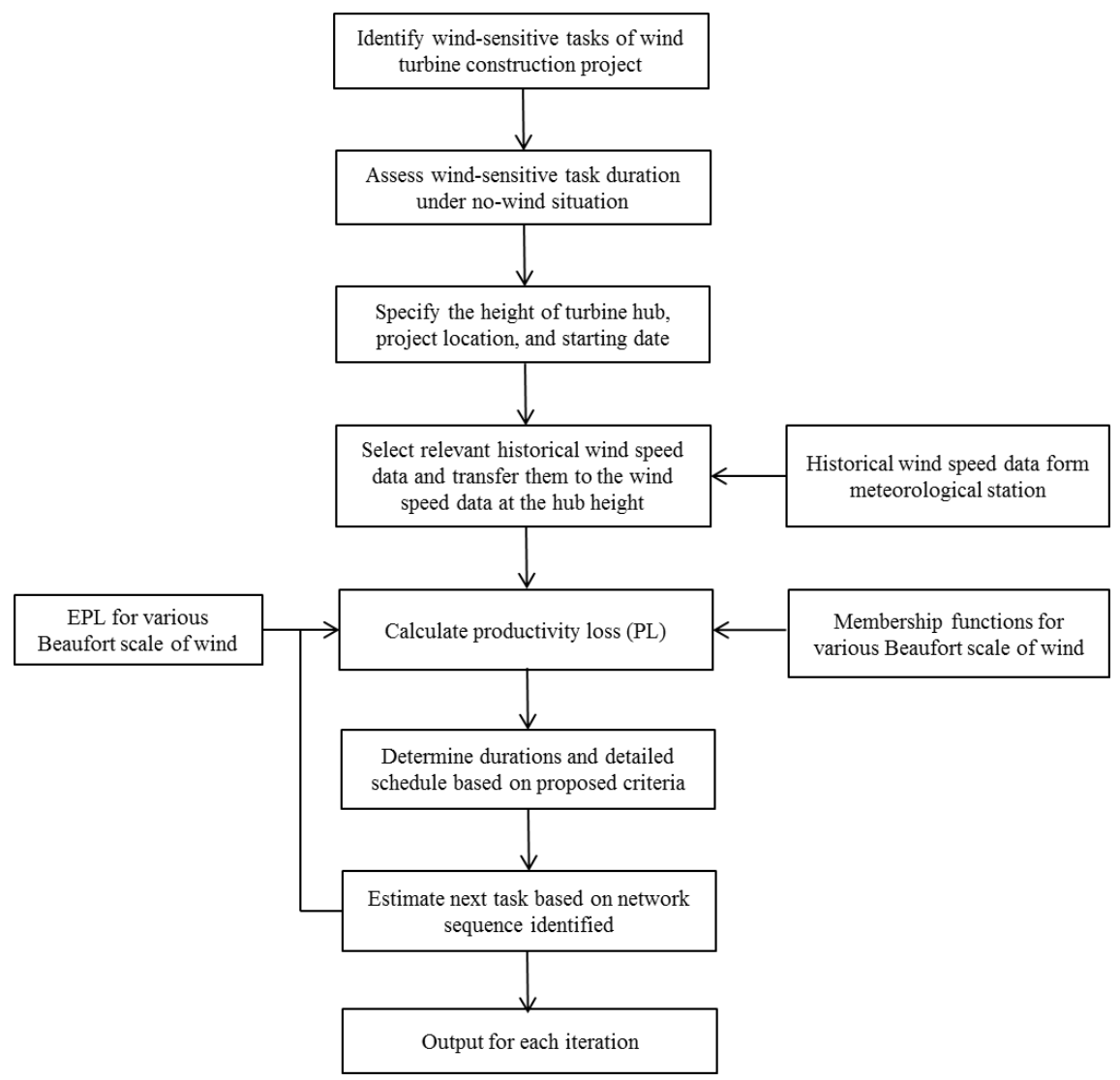

Figure 2. Framework for fuzzy duration management model.

demonstrate practical application of the model. The durations estimated by professional expertise are also compared with the durations simulated by this fuzzy duration forecast model. According to the comparisons, professionals unfamiliar with wind pattern in certain area may underestimate or overestimate the impact of wind uncertainty. Through the proposed model, the scheduler can assign more realistic and accurate duration required for wind-sensitive tasks while considering the impact of wind uncertainty.

Finally, through the results of various scenarios, another important finding in this study is that the effect of northeast monsoon becomes a critical impact factor for schedule risk management of wind turbine construction project. To avoid the adverse impact of northeast monsoon, the task of "Erection of Tower of Wind Turbine" and the task of "Cable Laying \& Wiring in Tower \& Nacelle" should be scheduled to be completed before the coming period of northeast monsoon. Afterwards, on the other hand, the task of "Commissioning Test \& Inspection" and the task of "Test Run \& 96-hr Trial Operation" should be scheduled in the period of northeast monsoon in order to face the positive influence of northeast monsoon. The results of application example demonstrate that only June or July would be the best suited period to start the task of "Erection of Tower of Wind Turbine" for wind turbine construction project in Taiwan. This insight provides owner and contractor with valuable knowledge to plan and 
manage contract schedule for wind turbine construction project. By means of the proposed fuzzy duration forecast model with historical wind speed data at the hub heights incorporated, the wind turbine construction projects can be executed more effectively and efficiently without suffering incontrollable delay penalty and contract disputes.

\section{Conflicts of Interest}

The author declares no conflicts of interest regarding the publication of this paper.

\section{References}

[1] Guo, S.J. (2000) Computer-Aided Project Duration Forecasting Subjected to the Impact of Rain. Journal of Computer-Aided Civil and Infrastructure Engineering, 15, 67-74. https://doi.org/10.1111/0885-9507.00172

[2] El-Rayes, K. and Moselhi, O. (2001) Impact of Rainfall on the Productivity of Highway Construction. Journal of Construction Engineering and Management, 127, 125-131. https://doi.org/10.1061/(ASCE)0733-9364(2001)127:2(125)

[3] Apipattanavis, S., Sabol, K., Molenaar, K.R., Rajagopalan, B., Xi, Y., Blackard, B. and Patil, S. (2010) Integrated Framework for Quantifying and Predicting Weather-Related Highway Construction Delays. Journal of Construction Engineering and Management, 136, 1160-1168.

https://doi.org/10.1061/(ASCE)CO.1943-7862.0000199

[4] Guo, S.-J., Chen, J.-H. and Chiu, C.-H. (2017) Fuzzy Duration Forecast Model for Wind Turbine Construction Project Subject to the Impact of Wind Uncertainty. Journal of Automation and Construction, 81, 401-410. https://doi.org/10.1016/j.autcon.2017.03.009

[5] Chao, L.C. and Hsiao, C.S. (2012) Fuzzy Model for Predicting Project Performance Based on Procurement Experiences. Automation in Construction, 28, 71-81. https://doi.org/10.1016/j.autcon.2012.07.003 